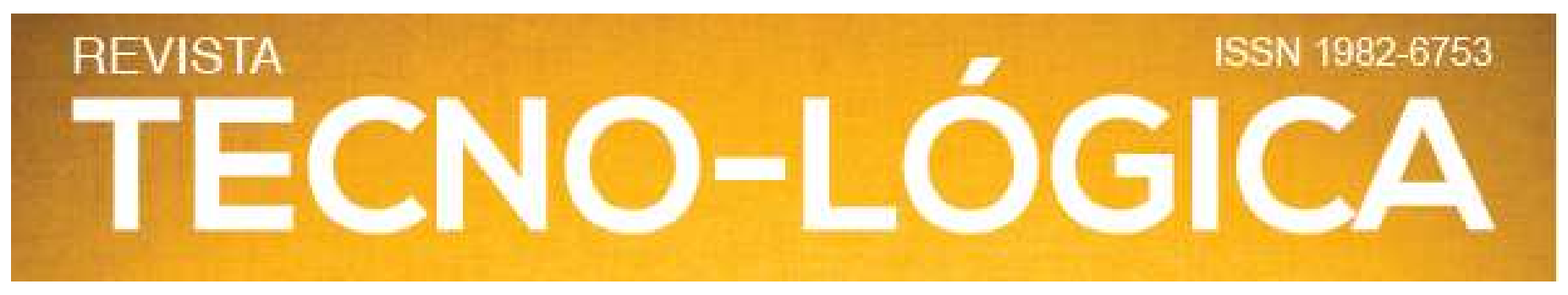

\title{
ESTIMATIVA DE FALHAS EM SEMEADURA DE SOJA (GLYCINE MAX (L) MERRILL) A PARTIR DE IMAGENS DE SENSORIAMENTO
}

\author{
Jonathas Mateus Wouters ${ }^{1}$, Elódio Sebem ${ }^{2}$
}

1 Programa de Pós-Graduação em Agricultura de Precisão, PPGAP - UFSM - Colégio Politécnico da UFSM, 97105-900, Santa Maria, Brasil.

2 Depto da Construção Civil -IFSC Campus Florianópolis, Av. Mauro Ramos, 950 - Centro, 88020-300, Florianópolis, SC, Brasil.

*E-mail: elodio.sebem@ifsc.edu.br

Recebido em: 02/11/2020

Aceito em: 26/12/2020

DOI: 10.17058/tecnolog.v25i1.15906

\section{RESUMO}

Atualmente, é notório o uso de aeronaves controladas remotamente na agricultura e a necessidade de cada vez mais otimizar a produção das lavouras brasileiras. Com esse intuito, o trabalho busca identificar falhas de semeadura a partir da interpretação de imagens obtidas com veículo aéreo não tripulado. Neste trabalho, as imagens foram obtidas nas alturas de voo de 60, 90 e 120 metros, e em quatro momentos pós-plantio, 15, 22, 32 e 37 dias após a semeadura, o processamento foi realizado no software QGIS gerando imagens com o percentual de cobertura pelas plantas de soja. Analisando as imagens classificadas, foi possível estimar o desenvolvimento das plantas de soja, constatou-se que não houve diferença significativa entre as alturas de voo, sendo assim a melhor altura para avaliar as falhas de semeadura foi a de 120 metros, por possibilitar uma maior área coberta em um mesmo voo. O voo que melhor representou o percentual de cobertura das plantas de soja foi o quarto (37 após a semeadura), visto que ocorreu logo após o efeito de uma aplicação de herbicida tornando a classificação mais eficiente sem a presença de daninhas.

Palavras-chave: Drone. Alta Resolução Espacial. Processamento Digital de Imagens. Análise Estatística. Agricultura de Precisão.

\section{Introdução}

No mundo não é novidade a grande preocupação com o aumento mundial da população e, em consequência disso, o considerável aumento da demanda por alimentos. Nesse contexto, existem diversas discussões sobre os impactos que a agricultura causa e pode causar, entre eles podemos citar o desmatamento das

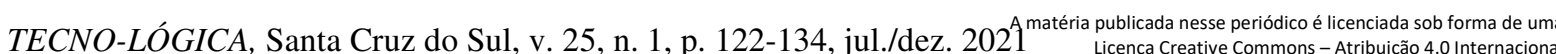
http://creativecommons.org/licenses/by/4.0/ 


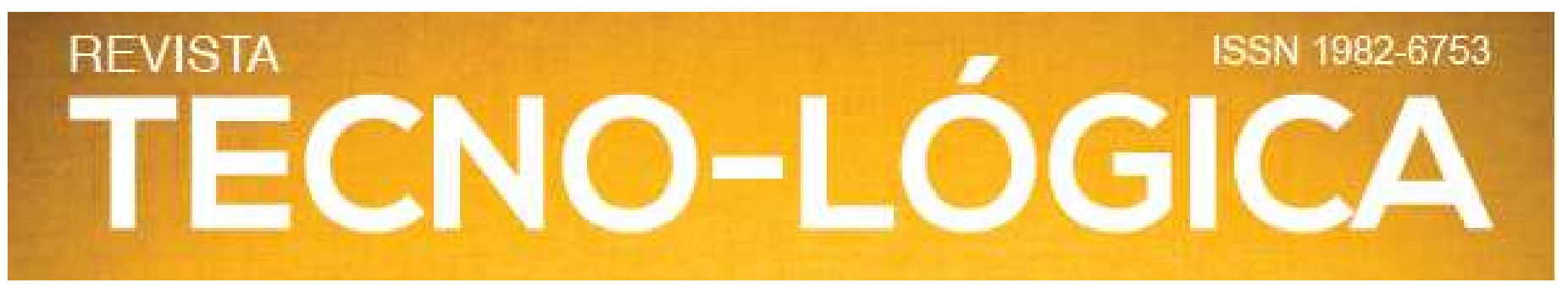

florestas, as queimadas, a degradação dos solos, a destruição da fauna, a poluição das águas, entre outros.

Diante de tal cenário, a Agricultura de Precisão (AP) que já é realidade no mundo e no Brasil, surgiu com o conceito de que existe variabilidade nas lavouras, independente dos seus tamanhos [1]. A AP traz a sistemática de identificar variações de solo, relevo, fertilidade, vegetação, histórico de uso, incidência de pragas e manejo de cada local de forma individualizada ou definição de zonas de manejo para conduzir da maneira mais adequada cada gleba da lavoura, com o intuito de aumentar a qualidade, a produtividade, a conservação do sistema, e assim, consequentemente, a rentabilidade do produtor [2].

A AP é um ramo relativamente recente, tendo como as tecnologias de monitores de colheita as que mais receberam atenção no início das pesquisas, pois proporcionam a primeira investigação da variabilidade espacial nas lavouras. As pesquisas mais recentes trazem perspectivas mais promissoras em termos de inovação, como o sensoriamento remoto, os sensores de plantas daninhas, entre outros sensores [3]. Também é considerada um sistema de gerenciamento agrícola que se baseia em tecnologias com intuito de proporcionar um manejo especializado nos fatores de produção, coletando informações georreferenciadas trazendo à tona a variabilidade espacial presente nas lavouras para que possam ser corrigidas da melhor forma possível [4].
Mesmo com uma enorme gama de benefícios, a AP ainda não é adotada na maioria das lavouras do país, e isso se deve ao fato de o aprimoramento das máquinas não ser acompanhado pela qualificação de mão-de-obra especializada [5]. A adoção da AP ocorre em um ritmo muito inferior ao previsto [6]. Em contraponto, estudos apontam para a crescente utilização de imagens de sensores remotos, principalmente de satélites bem como de VANTs na AP, destacam-se como tecnologia emergente pois possibilitam a tomada de decisão praticamente em tempo real [7].

A soja, um dos principais produtos agrícolas do Brasil segundo maior produtor mundial da leguminosa - possui enorme importância e influência na economia do País [8], assim demandando grande atenção em relação à cultura. A melhor relação produtividade - conservação ambiental - viabilidade econômica (lucro) é o objetivo a ser alcançado, porém é necessário ressaltar que existem diversos fatores inseridos em todo o processo de produção.

A semeadura, a emergência e o estabelecimento inicial da plântula são fatores determinantes para densidade, estande, e arranjo de plantas que consequentemente irão interferir na produtividade final. Dessa forma, a ocorrência de falhas na semeadura/plantio, fator muitas vezes não considerado na decisão do número de sementes a serem semeadas por metro linear e na

TECNO-LÓGICA, Santa Cruz do Sul, v. 25, n. 1, p. 122-134, jul./dez. $2021^{\text {Amatéria publicada nesse periódico é licenciada sob forma de uma }}$ 


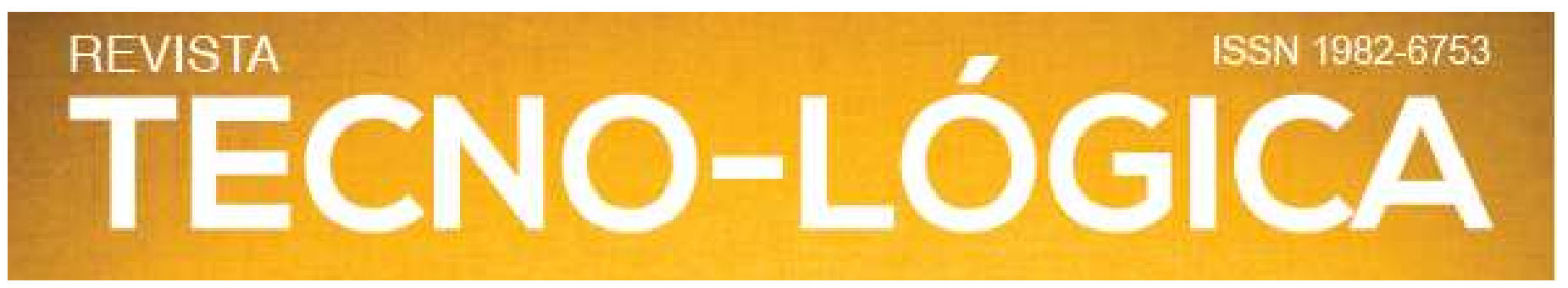

estimativa da população final, pode ocasionar uma grande redução da produtividade na lavoura [9].

A variabilidade nas lavouras é diversa, os elementos para que ela aconteça são inúmeros; sendo assim, neste trabalho, buscase uma forma de estimar o percentual de falhas de semeadura a partir da interpretação de imagens obtidas com veículo aéreo não tripulado (VANT), ferramenta muito utilizada nos dias atuais. Os Veículos Aéreos Não Tripulados (VANTs), em inglês conhecidos como Unmanned Aerial Vehicles (UAVs), são veículos controlados, que executam voos autônomos, semiautônomos ou guiados manualmente por controle remoto e se diferenciam das aeronaves tripuladas principalmente pelo fato da ausência do piloto[10]. O grande desafio era tornar os VANTs acessíveis para a população civil, assim evidenciando a necessidade de reduzir os custos de desenvolvimento e operação [11]. Os custos de um VANT reduziram de forma rápida com o passar dos anos, e atualmente o custo para adquirir o equipamento não é tão alto quando comparado à quantidade de serviços que se pode executar e à velocidade de execução em relação às formas tradicionais de trabalho [12].

O estudo se justifica pelo fato de as câmeras RGB serem o padrão de fábrica da maioria de modelos de VANT e, assim, muito mais acessíveis em comparação às câmeras multiespectrais com sensores infravermelhos, que apresentam um elevado custo de aquisição no mercado nacional, mas que, em contrapartida, fornecem a detecção remota de bandas usadas na determinação de Índices de Vegetação por Diferença Normalizada (NDVI), por exemplo.

\section{Metodologia}

O estudo foi conduzido no ano agrícola de 2018/2019, na área nova da Universidzade Federal de Santa Maria (UFSM) localizada no distrito de Pains no município de Santa Maria - Rio Grande do Sul - Brasil. Situado na região Central, com localização geográfica $29^{\circ} 43^{\prime} 14,59^{\prime \prime}$ S, 5344'57,90'’ O e altitude ortométrica média (em relação ao nível médio dos mares) de 100 m. O talhão de estudo possui 8,6 hectares, e foi semeado no dia 4 de dezembro da safra agrícola 2018/2019, com a cultivar BRS5601RR e população média de 300 mil plantas por hectare.

Os voos foram realizados nos dias 19 e 26 de dezembro de 2018 (15 e 22 dias após a semeadura, respectivamente) e nos dias 5 e 10 de janeiro de 2019 (32 e 37 dias após a semeadura, respectivamente). Em cada dia, foram realizados três voos: um com altura de 60 metros, gerando um tamanho de pixel de 3,0 cm; um com altura de 90 metros, gerando um pixel de 4,0 cm; e um de 120 metros, gerando um pixel de $5,5 \mathrm{~cm}$, totalizando doze voos.

TECNO-LÓGICA, Santa Cruz do Sul, v. 25, n. 1, p. 122-134, jul./dez. 2021 Amatéria publicada nesse periódico é licenciada sob forma de um http://creativecommons.org/licenses/by/4.0/ 


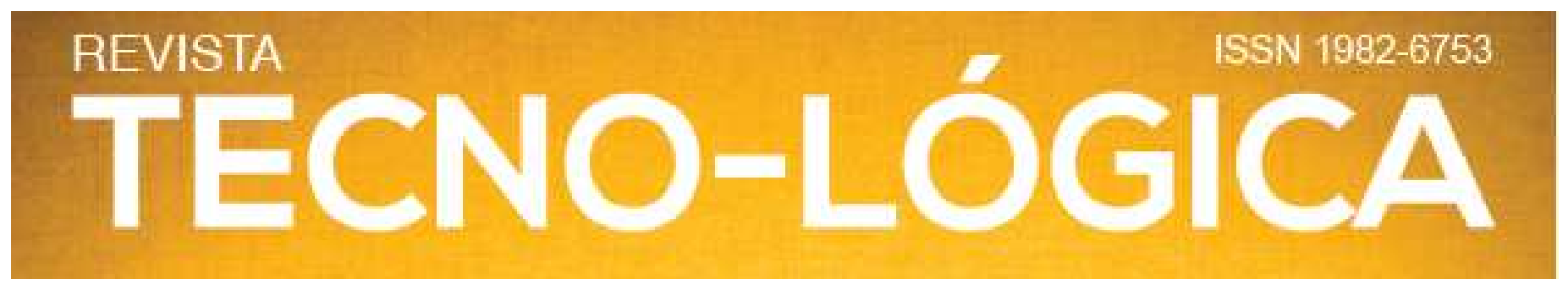

Para obtenção de imagens, foi utilizado o VANT DJI Phantom 4 com câmera RGB embarcada, resolução espacial de 20 MP, sensor CMOS de 1", taxa de abertura f/2.8. Os parâmetros utilizados para a realização do voo foram um recobrimento lateral de $70 \%$ e um recobrimento longitudinal de $80 \%$, além de 6 pontos de controle para geração do ortomosaico de imagens georreferenciamento pelo software Agisoft PhotoScan 1.4.2.

Os ortomosaicos foram processados utilizando o plugin SCP (Semi-Automatic Classification Plugin) do QGIS. Nessa função, foram criadas duas classes, uma de "Soja" e a outra de “Área sem Soja”, assim, coletaram-se 25 amostras para cada classe. Após, foi realizado o processamento e, então, gerou-se uma imagem com apenas dois tipos de pixels: um com soja presente e outro com os demais elementos.

Em seguida, no mesmo plugin, foi aplicada a função classification sieve que é um filtro para eliminar os pixels isolados e deixar as áreas mais homogêneas. Nesse momento, foi possível incluir duas variáveis: size threshold (número de pixels conectados que podem ser substituídos pelo valor mais abundante de seus vizinhos) e pixel connection (opções: $4=$ em uma janela de $3 \times 3$, os pixels das diagonais não são considerados conectados e $8=\mathrm{em}$ uma janela de $3 \times 3$, os pixels das diagonais são considerados conectados). Foram usadas três variações size threshold/pixel connection, respectivamente: 4/4, 4/8 e 8/4.
Para avaliação mais detalhada das imagens, foram criadas aleatoriamente 45 amostras dentro do perímetro da área de estudo, cada uma delas consistindo em um quadrado de cinco por cinco metros. Dentro de cada quadrado, foram vetorizadas as linhas de plantio e, em seguida, aplicada uma área de influência (buffer) de 3; 4 e 5,5 centímetros (de acordo com o tamanho do pixel das imagens em cada altura de voo $60 \mathrm{~m}, 90 \mathrm{~m}$ e $129 \mathrm{~m}$, respectivamente). Esses buffers foram utilizados para recortar as imagens classificadas e filtradas.

Para quantificar os pixels de cada classe, foi aplicada a função "Zonal Histogram” do software QGIS, gerando assim um arquivo shapfile contendo a quantidade de pixels para cada classe em cada uma das amostras de cada uma das imagens em cada voo.

\section{Resultados e discussões}

3.1 Análise da germinação e do estabelecimento das plantas de soja

Para avaliação mais detalhada das falhas de semeadura nas imagens, foram criadas aleatoriamente 45 amostras dentro da área de estudo, cada uma delas consistindo em um quadrado de cinco por cinco metros. Nestes pontos, foram vetorizadas as linhas de plantio e posteriormente efetuada a criação de buffers. Nesse procedimento, o ponto a ser ressaltado é a largura desta área de influência (distância), foram usados respectivamente 3; 4 e 5,5

TECNO-LÓGICA, Santa Cruz do Sul, v. 25, n. 1, p. 122-134, jul./dez. $2021^{\text {Amatéria publicada nesse periódico é licenciada sob forma de uma }}$ 


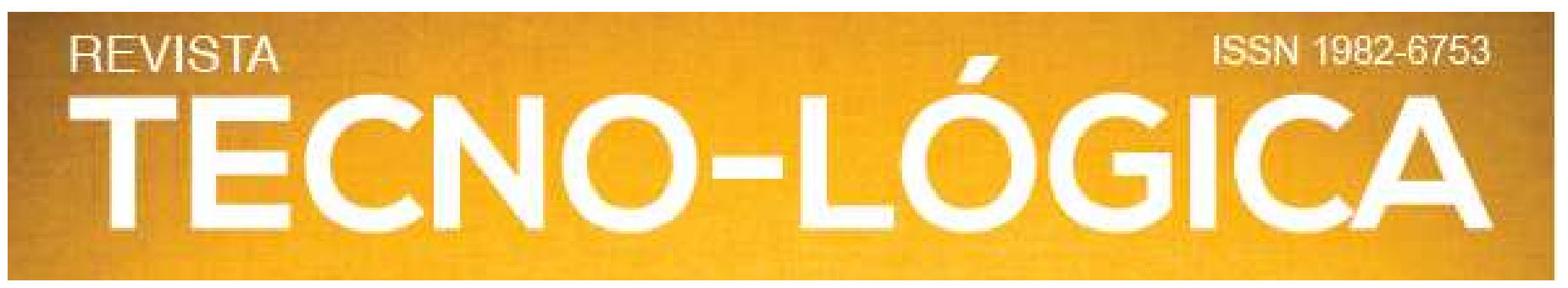

centímetros para serem utilizados em processamentos posteriores nas alturas de voo 60, 90 e 120 metros, esses parâmetros foram definidos com base no tamanho de pixel de cada imagem.

As linhas de plantio, agora transformadas em polígonos devido à aplicação do buffer, foram utilizadas para recortar as imagens já processadas e pós processadas. A função descrita gerou três imagens para cada altura e em cada data de voo, assim totalizando trinta e seis imagens recortadas. Essas imagens possuem três tipos de informação conforme descrito anteriormente, pixels classificados com área coberta por soja, pixels compostos por outros elementos e pixels sem informação (fora dos buffers).

Para quantificar os pixels de cada classe, foi gerado um arquivo no formato shapfile que contém a quantidade de pixels para cada classe em cada uma das amostras de cada uma das imagens em cada voo. A função descrita realiza uma contagem da quantidade de pixels que cada uma das classes possui. Assim, obteve-se o número de pixels tanto para a classe "soja" quanto para a classe "outro", entretanto, o objetivo deste trabalho é mapear/identificar o desenvolvimento da soja, então, calculou-se a porcentagem de pixels cobertos pelas plantas da cultura da soja gerando o percentual de cobertura em cada uma das imagens de cada voo em cada um dos pós processamentos.
Sobre a média dos valores, aplicou-se teste para a diferença entre duas proporções populacionais, que é um teste de comparação de hipóteses. Nesse teste, foram comparadas entre si as médias das proporções de área ocupada por soja para a aplicação do filtro 44, do filtro 48 e do filtro 84 e conclui-se que não há diferença estatística entre elas. Portanto, passaremos a analisar apenas as imagens pós processadas com o filtro 84 por apresentar um melhor resultado visual.

O teste de diferença de médias populacionais entre as médias dos percentuais de cobertura da soja também foi aplicado entre as diferentes alturas de voo e para todos os voos. Constatouse que não houve diferença estatística apenas na comparação entre as alturas de 60 e 120 metros no segundo voo deste trabalho. Dessa forma, entende-se que o tamanho de pixel não influenciou na identificação da germinação das plantas de soja, e, portanto, é possível utilizar a altura de voo de 120 metros para buscar falhas na semeadura sem prejuízo no resultado do trabalho. Voos a 120 metros de altura são mais interessantes do ponto de vista estratégico e operacional a fim de otimizar o uso da tecnologia, sendo assim a partir deste ponto serão apresentados os percentuais de cobertura obtidos para esta altura.

Na tabela 1 a seguir, podemos visualizar os percentuais de cobertura das plantas de soja para a altura de 120 metros no primeiro, segundo, terceiro e quarto voo, em cada ponto amostral. TECNO-LÓGICA, Santa Cruz do Sul, v. 25, n. 1, p. 122-134, jul./dez. $2021^{\text {A matéria publicada nesse periódico é licenciada sob forma de uma }}$ Licença Creative Commons - Atribuição 4.0 Internacional http://creativecommons.org/licenses/by/4.0/ 


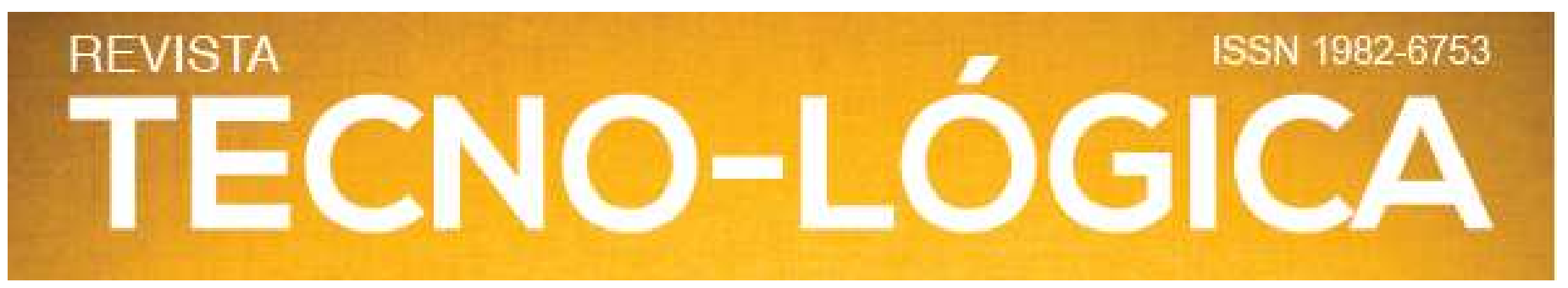

Na quarta, quinta e sexta coluna, são apresentados os percentuais de cobertura das plantas de soja em cada ponto amostral, já o título no cabeçalho significa respectivamente, número do voo, altura de voo, procedimento de suavização e classe amostral.

Assim como nos dados anteriores, também foi aplicado o teste de diferença de médias populacionais entre as médias dos percentuais de cobertura da soja entre as diferentes datas de voo na altura de 120 metros. Observou-se diferença estatística apenas na comparação entre o primeiro e o segundo voo, o que mostra uma clara evolução no percentual de cobertura da soja. Já na comparação entre o terceiro e o quarto voo, não ocorreu diferença estatística, entretanto é notável a redução no percentual médio de cobertura (Figura 1).

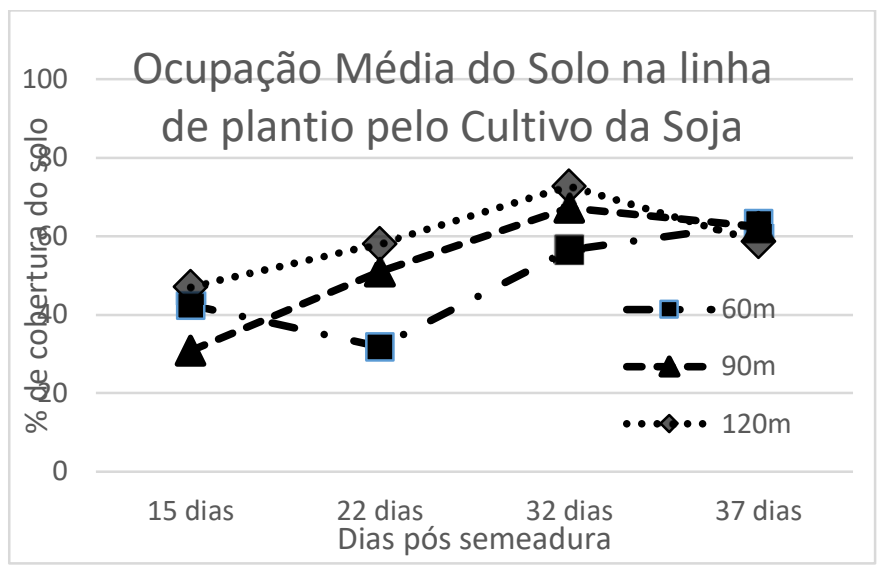

Figura 1 - Evolução média do percentual de cobertura da cultura da soja.
$\mathrm{Na}$ figura acima, visualiza-se de forma mais clara a evolução das plantas de soja, ocorre um aumento gradual na média de cobertura das plantas até o terceiro voo, porém no quarto voo há uma queda significativa nessas médias, mesmo que as médias de forma geral convergissem para um percentual muito próximo em ambos os voos.

O que pode explicar esta redução na média percentual de cobertura no quarto voo é uma aplicação de herbicida realizada entre o segundo e o terceiro voo. Trata-se de um herbicida de ação sistêmica (dessecante), usado com intuito de eliminar plantas daninhas presentes em meio a lavoura, que atua inibindo uma determinada enzima da via metabólica a qual impede a síntese de aminoácidos essenciais para o crescimento das plantas, o que faz a vegetação invasora "secar" lentamente e morrer, sendo decomposta com o passar do tempo. Tal processo reduziu o número de plantas presentes no quarto voo e, consequentemente, podendo ter reduzido os valores da classe de soja, visto que no procedimento de classificação das imagens algumas plantas daninhas com propriedades espectrais similares as plantas de soja podem ter sido contabilizadas na classe de soja mascarando o percentual de cobertura dos voos anteriores. TECNO-LÓGICA, Santa Cruz do Sul, v. 25, n. 1, p. 122-134, jul./dez. 2021 Aatéria publicada nesse periódico é licenciada sob forma de um http://creativecommons.org/licenses/by/4.0/ 


\begin{tabular}{|c|c|c|c|c|c|}
\hline \multirow{2}{*}{$\begin{array}{c}\text { Ponto } \\
\text { amostral }\end{array}$} & \multicolumn{2}{|c|}{ Coordenadas } & \multicolumn{3}{|c|}{ Pós-processamento } \\
\hline & $\mathbf{E}$ & $\mathbf{N}$ & $4 / 4$ & $4 / 8$ & $8 / 4$ \\
\hline 1 & 234070 & 6709191 & 67,24 & 66,22 & 69,76 \\
\hline 2 & 234073 & 6709132 & 79,40 & 78,98 & 80,31 \\
\hline 3 & 233963 & 6709085 & 59,29 & 59,21 & 61,93 \\
\hline 4 & 233954 & 6709069 & 67,41 & 67,90 & 67,84 \\
\hline 5 & 233941 & 6709050 & 61,89 & 60,96 & 64,89 \\
\hline 6 & 233952 & 6709039 & 60,58 & 60,18 & 62,95 \\
\hline 7 & 233963 & 6709038 & 56,00 & 55,19 & 55,59 \\
\hline 8 & 234019 & 6709044 & 45,33 & 46,03 & 45,46 \\
\hline 9 & 234033 & 6709052 & 67,95 & 67,23 & 69,26 \\
\hline 10 & 234049 & 6709035 & 65,77 & 65,51 & 66,73 \\
\hline 11 & 234140 & 6709076 & 64,25 & 63,55 & 65,35 \\
\hline 12 & 234159 & 6709059 & 40,18 & 40,33 & 40,25 \\
\hline 13 & 234112 & 6709038 & 71,21 & 70,73 & 71,49 \\
\hline 14 & 234161 & 6709017 & 62,51 & 62,53 & 62,27 \\
\hline 15 & 234183 & 6709036 & 36,12 & 36,09 & 34,67 \\
\hline 16 & 234080 & 6708955 & 27,99 & 28,20 & 26,31 \\
\hline 17 & 234094 & 6708924 & 41,13 & 41,21 & 40,97 \\
\hline 18 & 234119 & 6708891 & 75,83 & 74,87 & 76,74 \\
\hline 19 & 234105 & 6708895 & 33,13 & 33,51 & 31,28 \\
\hline 20 & 234088 & 6708888 & 36,45 & 36,37 & 35,33 \\
\hline 21 & 234117 & 6708871 & 29,37 & 29,49 & 27,37 \\
\hline 22 & 234031 & 6708940 & 32,55 & 32,55 & 30,03 \\
\hline 23 & 234002 & 6708946 & 47,98 & 46,91 & 48,06 \\
\hline
\end{tabular}

\begin{tabular}{|c|c|c|c|c|c|}
\hline \multirow{2}{*}{$\begin{array}{c}\text { Ponto } \\
\text { amostral }\end{array}$} & \multicolumn{2}{|c|}{ Coordenadas } & \multicolumn{3}{|c|}{ Pós-processamento } \\
\hline & $\mathbf{E}$ & $\mathbf{N}$ & $4 / 4$ & $4 / 8$ & $8 / 4$ \\
\hline 24 & 233958 & 6709009 & 64,51 & 64,19 & 64,69 \\
\hline 25 & 233900 & 6709059 & 71,17 & 70,67 & 71,11 \\
\hline 26 & 233886 & 6709057 & 24,69 & 25,04 & 23,32 \\
\hline 27 & 233915 & 6709082 & 62,84 & 62,84 & 62,71 \\
\hline 28 & 233907 & 6709004 & 37,73 & 38,21 & 37,18 \\
\hline 29 & 233867 & 6709030 & 8,57 & 8,41 & 8,20 \\
\hline 30 & 234155 & 6708991 & 44,81 & 45,07 & 44,71 \\
\hline 31 & 233900 & 6709024 & 28,96 & 29,31 & 27,97 \\
\hline 32 & 233934 & 6708969 & 22,15 & 22,15 & 22,00 \\
\hline 33 & 234001 & 6708955 & 69,78 & 69,53 & 70,15 \\
\hline 34 & 234021 & 6708975 & 3,42 & 3,42 & 2,94 \\
\hline 35 & 234026 & 6709009 & 14,13 & 14,30 & 13,59 \\
\hline 36 & 234106 & 6709004 & 13,80 & 14,41 & 12,86 \\
\hline 37 & 234170 & 6708960 & 71,68 & 71,79 & 71,57 \\
\hline 38 & 234156 & 6708909 & 19,49 & 20,34 & 18,94 \\
\hline 39 & 234138 & 6708926 & 10,98 & 11,41 & 10,32 \\
\hline 40 & 234137 & 6709033 & 8,17 & 8,33 & 7,74 \\
\hline 41 & 234156 & 6709035 & 21,96 & 22,39 & 21,66 \\
\hline 42 & 234100 & 6709139 & 5,17 & 6,06 & 4,25 \\
\hline 43 & 234043 & 6709154 & 39,81 & 39,88 & 39,73 \\
\hline 44 & 234028 & 6709060 & 17,07 & 17,12 & 15,53 \\
\hline \multirow[t]{2}{*}{45} & 234006 & 6709052 & 23,84 & 24,13 & 23,42 \\
\hline & & Iédia/100 = & 0,43 & 0,43 & 0,42 \\
\hline
\end{tabular}
TECNO-LÓGICA, Santa Cruz do Sul, v. 25, n. 1, p. 122-134, jul./dez. 2021 A matéria publicada nesse periódico é licenciada sob forma de uma http://creativecommons.org/licenses/by/4.0/ 


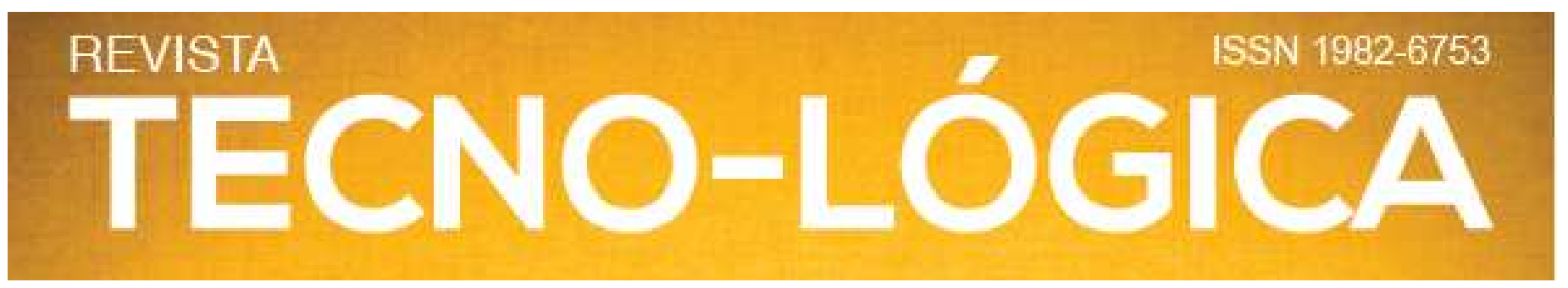

É possível também perceber uma queda brusca na média do percentual de cobertura do segundo voo na altura de 60 metros, neste caso pode ter ocorrido algum tipo de confusão na classificação e, devido a isso, o percentual do segundo foi menor que o percentual no primeiro. Essa queda pode estar ligada a fatores pluviométricos, pois, de acordo com dados de pluviometria do Instituto Nacional de Meteorologia (INMET), ocorreu uma fortíssima chuva previamente à realização do voo.

Além dos fatores meteorológicos, as plantas também sofrem influência do relevo, abaixo podemos visualizar o modelo digital do terreno (MDT) (Figura 2), o qual evidencia as declividades e o padrão do relevo da área de estudo.
A seguir, serão apresentados os mapas com os percentuais de cobertura das plantas de soja em cada um dos voos na altura de 120 metros para cada um dos pontos amostrais que estão representados na cor rosa (Figuras 3, 4, 5 e 6).

Na figura 3, pode-se visualizar o raio do percentual de cobertura da germinação das plantas de soja (na cor preta) no primeiro voo, em geral, temos uma média de $40 \%$ de recobrimento o que caracteriza uma boa germinação. Entretanto, temos alguns pontos com germinação acima de $60 \%$, por influência de plantas daninhas na lavoura, em contrapartida temos pontos com germinação inferior a 30\%, o que pode ser explicado por atraso na emergência das plantas, ou por falhas na semeadura.

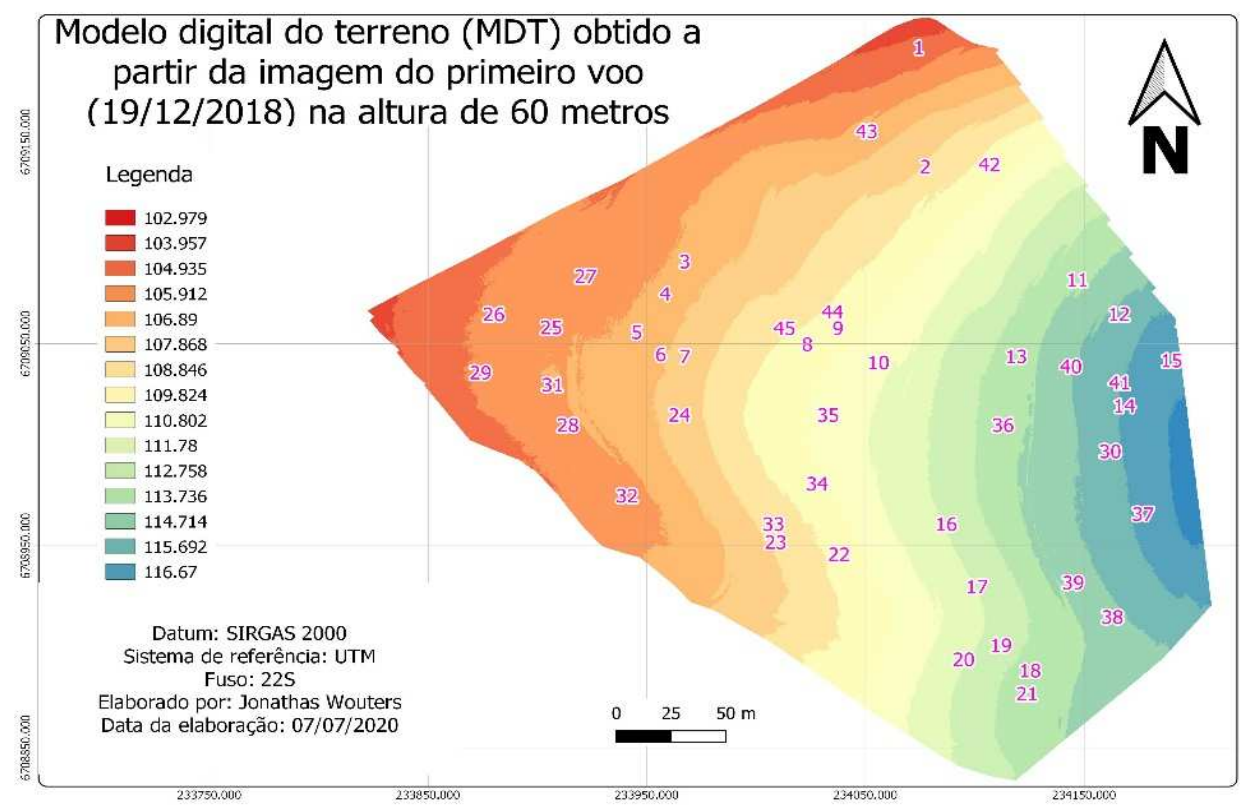

Figura 2 - Modelo digital do terreno obtido a partir da imagem do primeiro na altura de voo de 60 metros, com a presença dos pontos amostrais.

TECNO-LÓGICA, Santa Cruz do Sul, v. 25, n. 1, p. 122-134, jul./dez. $2021^{\text {Amatéria publicada nesse periódico é licenciada sob forma de um }}$ http://creativecommons.org/licenses/by/4.0/ 

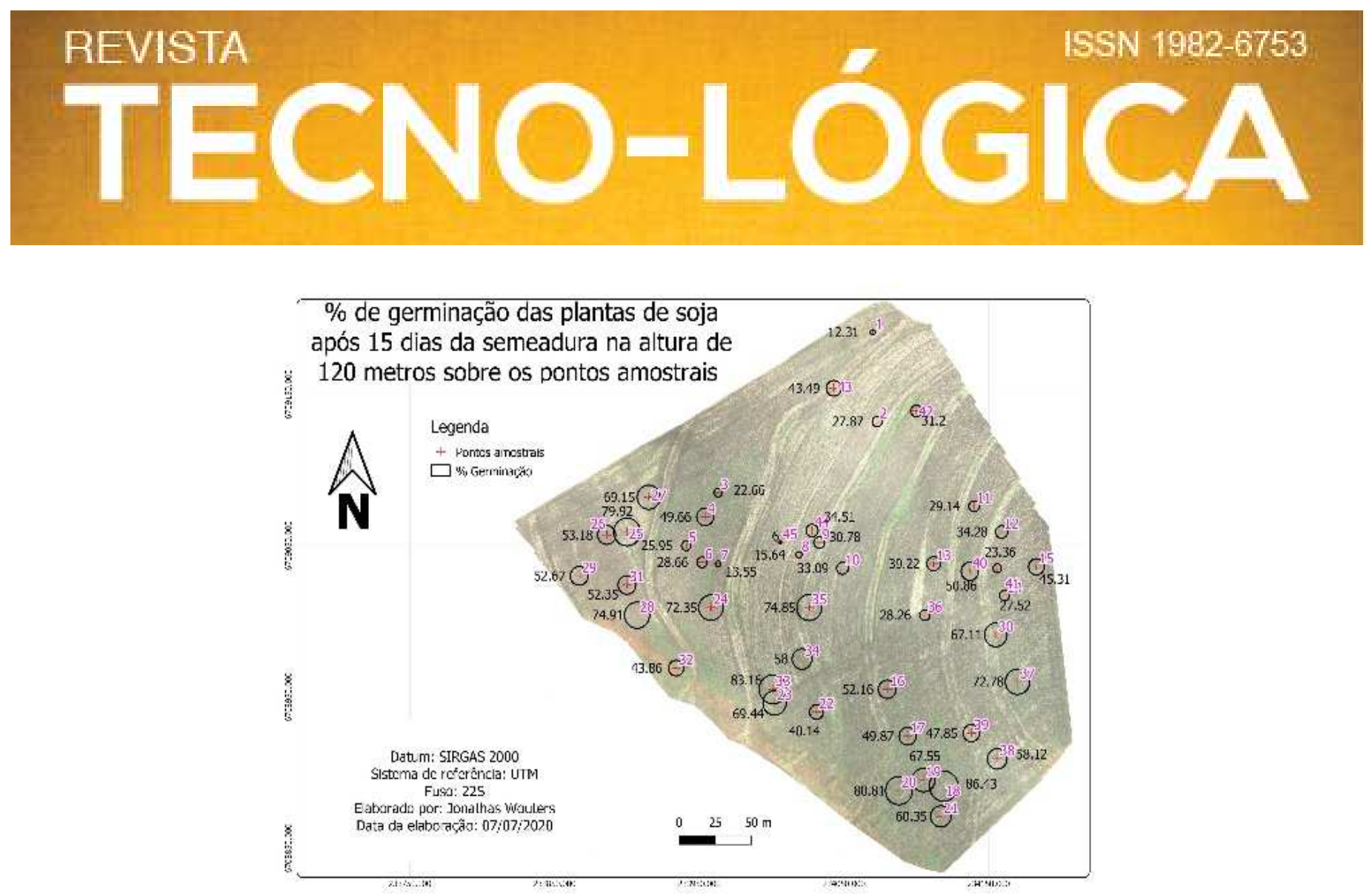

Figura 3 - Percentual de cobertura da cultura da soja 15 dias após a semeadura.

Já na figura 4, logo abaixo, nota-se um aumento geral nos percentuais de cobertura. $\mathrm{O}$ aumento é significativo, visto o rápido crescimento das plantas, no entanto em alguns pontos é percebível uma redução no percentual, o que pode ser explicado pela morte de algumas pela falta de vigor em conjunto com condições de solo e clima desfavoráveis.

Outro ponto a ressaltar, ainda na figura 4, pode ser visto na imagem de fundo, em que a presença de solo exposto começa a diminuir e também pode-se verificar um aumento na presença de daninhas.
$\mathrm{Na}$ figura 5, percebe-se um aumento ainda maior no percentual de cobertura em geral (circunferências na cor vermelha). As plantas estão bem maiores, contribuindo no aumento das porcentagens, e neste momento, quase nem se visualiza mais solo exposto na imagem de fundo. Também é possível identificar um tom "amarelado" na mesma, o que é devido a uma aplicação de herbicida, conforme já mencionado neste trabalho, o que faz com que as plantas daninhas entrem em senescência. Já na figura 6, o tom "amarelado" é menos aparente e aparecem novamente manchas de solo exposto, tal situação deve-

TECNO-LÓGICA, Santa Cruz do Sul, v. 25, n. 1, p. 122-134, jul./dez. 2021 Aatéria publicada nesse periódico é licenciada sob forma de um http://creativecommons.org/licenses/by/4.0/ 


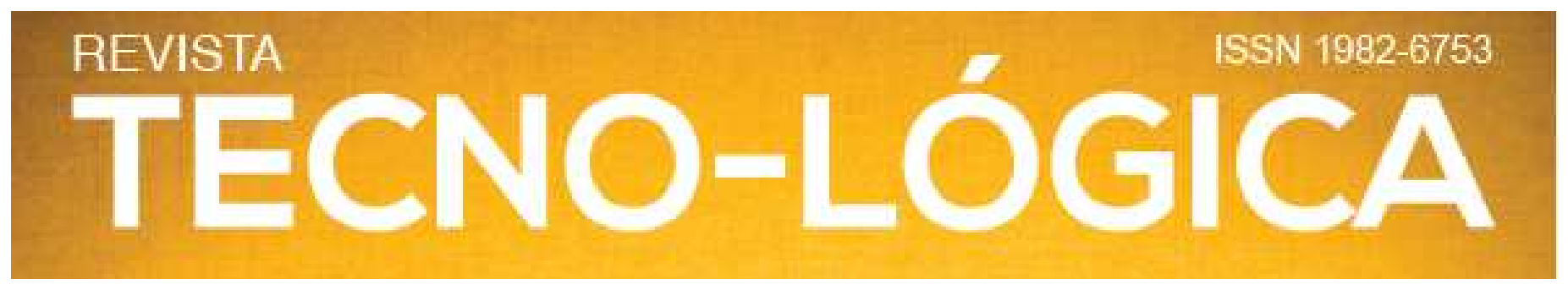

se à senescência das plantas daninhas, as quais pouco aparecem na imagem neste momento.

Na figura 6 , de modo geral, nota-se uma redução no percentual de cobertura plantas (circunferências na cor laranja), como já explicado devido as plantas daninhas não estarem mais influenciando (ou influenciando pouco) na classificação. Assim, as falhas de semeadura se tornam mais evidentes e, analisando mais profundamente, podemos perceber determinados pontos com baixo percentual de cobertura, mesmo sendo esses com percentual de cobertura razoável nos demais voos. Olhando individualmente para estes pontos com menor cobertura, encontram-se diversas falhas mecânicas de semeadura, como por exemplo falha intermitentes em uma ou duas linhas, devido a, muito provavelmente, canos da semeadora entupidos. Há alguns locais também em que diversas linhas de semeadura (supõem-se que as equivalentes à largura da semeadora) têm uma falha ininterrupta por determinada distância, o que é explicado por falha operacional onde muito provavelmente houve semeadura sem sementes nas caixas da semeadora.

Além das falhas na semeadura, ocorreu também um outro problema operacional na lavoura, ao contrário de falhas, houve sobreposição entre as linhas de semeadura, o que prejudica o estande de plantas e acaba aumentando o percentual de cobertura nas classificações.

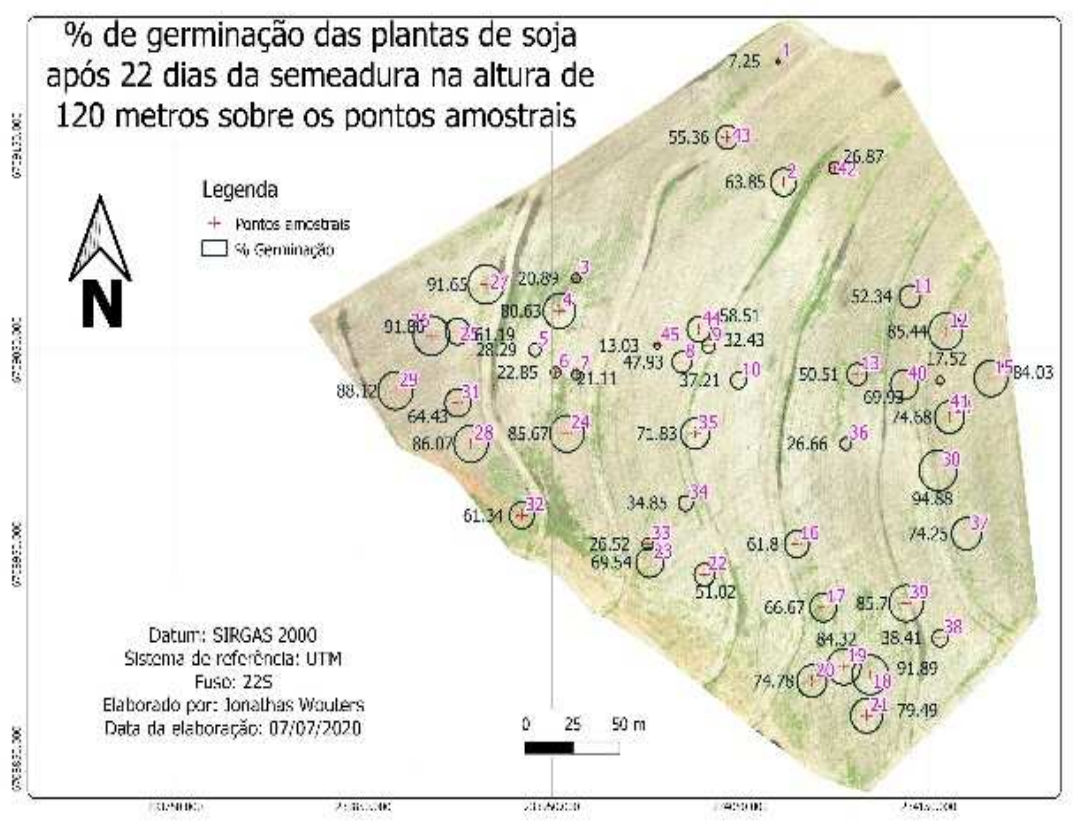

Figura 4 - Percentual de cobertura da cultura da soja 22 dias após a semeadura.

TECNO-LÓGICA, Santa Cruz do Sul, v. 25, n. 1, p. 122-134, jul./dez. $2021^{\text {Amatéria publicada nesse periódico é licenciada sob forma de uma }}$ http://creativecommons.org/licenses/by/4.0/ 

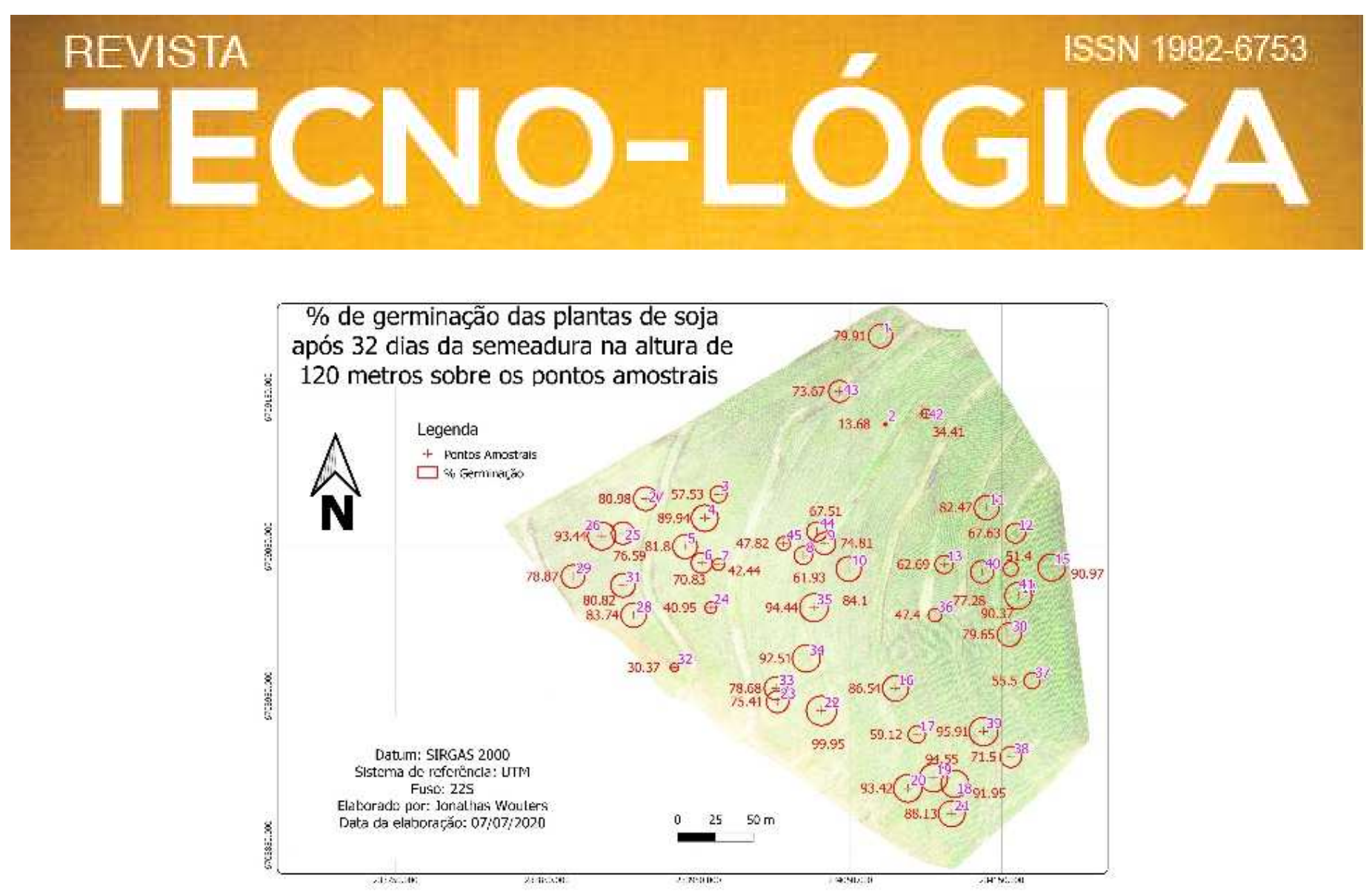

Figura 5 - Percentual de cobertura da cultura da soja 32 dias após a semeadura.

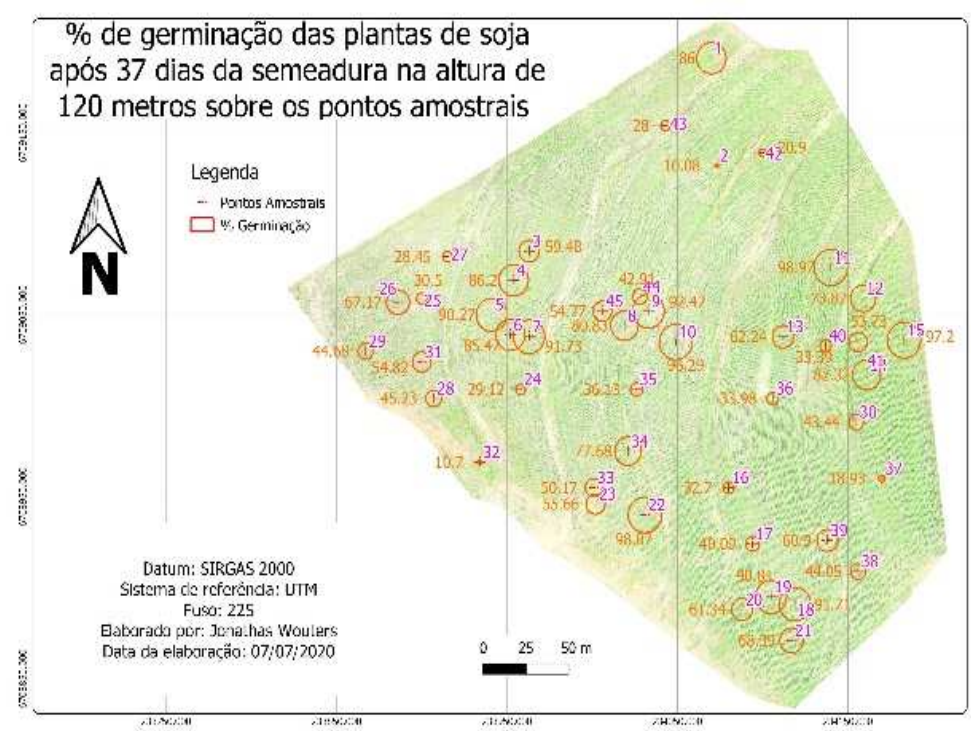

Figura 6 - Percentual de cobertura da cultura da soja 37 dias após a semeadura. TECNO-LÓGICA, Santa Cruz do Sul, v. 25, n. 1, p. 122-134, jul./dez. $2021^{\text {Amatéria publicada nesse periódico é licenciada sob forma de uma }}$ Licença Creative Commons-Atribuição 4.0 Internaciona 


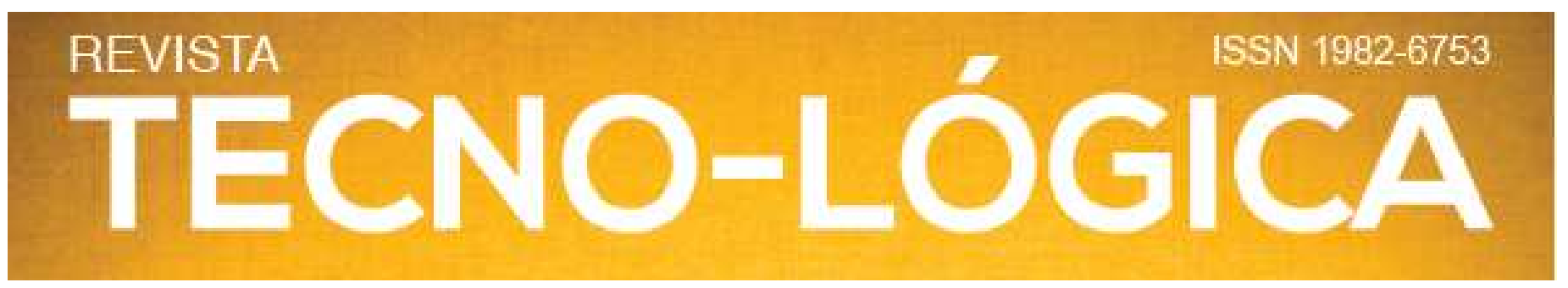

\section{Conclusões}

Tendo em vista os aspectos observados neste trabalho, foram obtidas imagens de alta resolução e, nestas, foram aplicadas técnicas de processamento digital com intuito de encontrar a melhor forma para estimar falhas de semeadura. Sendo assim, foi possível estimar o desenvolvimento das plantas de soja a partir da interpretação de imagens obtidas com VANT. Entretanto, alguns aspectos devem ser levados em consideração como, por exemplo, a presença de plantas daninhas, que podem mascarar a classificação.

Durante as análises, constatou-se que não há diferença significativa entre as alturas de voo. Dessa forma, a melhor altura para determinar as falhas de semeadura é a de 120 metros, devido a possibilitar uma maior área coberta em um mesmo voo.

Já entre as datas de voo, houve algumas diferenças. Porém, o voo que melhor representou o percentual de cobertura das plantas de soja foi o quarto, visto que ocorreu logo após o efeito de uma aplicação de herbicida tornando a classificação mais eficiente sem a presença de daninhas. Dessa forma, foi o melhor resultado encontrado no trabalho. Entretanto, com 37 dias após a semeadura, talvez não seja mais viável a realização de replantio, visto as plantas já estarem em estágio fenológico avançado. Nesse momento, um replantio prejudicaria muito a uniformidade da lavoura. A decisão a tomar neste momento seria realizar ou não uma nova semeadura da área total, no caso do trabalho, não seria necessária.

\section{ESTIMATION OF SEEDING FAILURES IN SOYBEAN}

\section{CULTURE WITH IMAGES FROM NON-CREWED AIR}

\section{VEHICLES}

ABSTRACT: Currently, there is a great use of remotely controlled aircraft in agriculture and the need to increasingly optimize the production of Brazilian crops. To this end, this work aimss to analyze the failures in sowing / planting in soybean crops from the interpretation of images obtained with this type of equipment. In this work, the images were obtained at flight heights of 60, 90 and 120 meters, and on four post-planting dates, 15, 22, 32 and 37 days after sowing, the processing was performed in the QGIS software generating images with the percentage of coverage by soybean plants. Analyzing the classified images it was possible to estimate the development of soybean plants, it was found that there was no significant difference between the flight heights, so the best time to evaluate sowing failures was 120 meters, as it allows a larger area covered on the same flight. The flight that best represented the coverage percentage of soybean plants was the fourth (37 after sowing), since it occurred right after the effect of

TECNO-LÓGICA, Santa Cruz do Sul, v. 25, n. 1, p. 122-134, jul./dez. 2021 A matéria publicada nesse periódico é licenciada sob forma de um http://creativecommons.org/licenses/by/4.0/ 


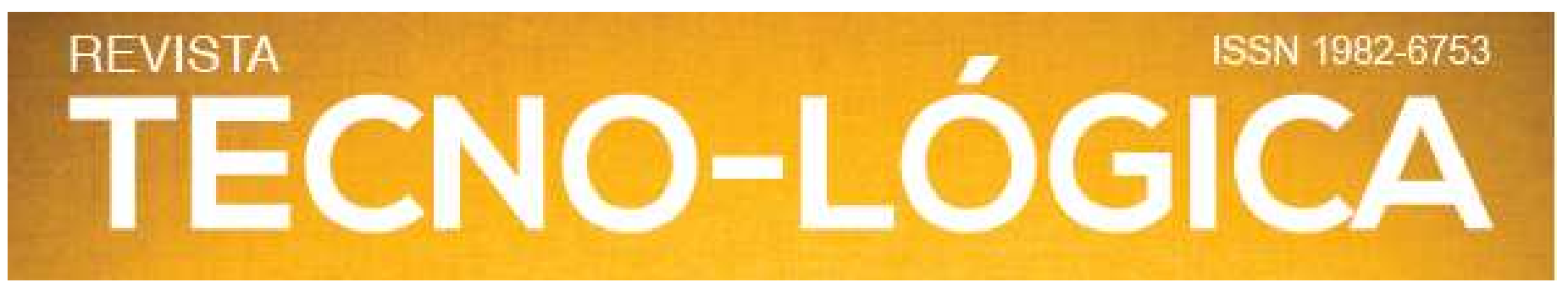

a herbicide application making the classification more efficient without the presence of weeds.

Keywords: Drone. High Spatial Resolution. Digital Image Processing. Statistical Analysis. Precision Agriculture.

\section{Referências}

[1] MOLIN, J. P. Geração e interpretação de mapas de produtividade para agricultura de precisão. In: BORÉM et. al. Agricultura de precisão Viçosa: UFV, 2000 .

[2] AMADO, T.J.C., SANTI, A.L. Agricultura de precisão aplicada ao aprimoramento do manejo do solo. In: FIORIN, J.E., ed. Manejo da fertilidade do solo no sistema plantio direto. Passo Fundo, Berthier, 2007. p.99-144.

[3] CASTRO, C. N. Definição de Unidades de Gerenciamento do Solo por Meio da Sua Condutividade Elétrica e Variáveis Físico-Químicas. 2004. 142 p. Dissertação (Mestrado em Agronomia) - Escola Superior de Agronomia "Luiz de Queiroz” Universidade de São Paulo, Piracicaba, RS, 2004.

[4] MENEGATTI, L.A.A. Metodologia para identificação, caracterização e remoção de erros em mapas de produtividade. Piracicaba, 2002. 95f. (Dissertação). Mestrado em Agronomia, Escola Superior de Agricultura "Luiz Queiroz", Universidade de São Paulo.

[5] MAPA. Agricultura de precisão. Secretaria de Desenvolvimento Agropecuário e Cooperativismo. Brasília: Mapa/ACS, 2013. Disponível em: <https://www.gov.br/agricultura/pt-br/assuntos/sustentabilidade/tecnologiaagropecuaria/agricultura-de-precisao-1/arquivos-de-agricultura-deprecisao/boletim-tecnico-agricultura-de-precisao-2013.pdf >. Acesso em: 11 de out de 2017.
[6] BERNARDI, A. C. de C.; NAIME, J. de M.; RESENDE, A. V. de; BASSOI,

L. H.; INAMASU, R. Y. (Ed.). Agricultura de precisão: resultados de um novo olhar. Brasília, DF: Embrapa, 2014. p. 109-134.

[7] COLOMINA, I.; MOLINA, P. Unnamed aerial systems for photogrammetry and remote sensing. A revie Journal of Phtogrammetry and Remote Sensing. v. 92, p.79-97, 2014

\section{[8] EMBRAPA - EMPRESA BRASILEIRA DE PESQUISA AGROPECUÁRIA} Produção de soja no Brasil. 2017. Disponível em: < https://www.embrapa.br/web/portal/busca-de-noticias/-

/noticia/25242861/producao-de-soja-no-brasil-cresce-mais-de-13-ao-ano>.

Acesso em: 8 de out. de 2017.

[9] PINTO, J.F. Comportamento de plantas de soja frente a falhas e duplas dentro de uma população. Pelotas, 2010. 45f. (Tese). Doutorado em Ciências, Programa de Pós-Graduação em Ciência e Tecnologia de Sementes, Universidade Federal de Pelotas.

[10] EISENBEISS, H. VANT Photogrammetry. Zurich, University of Technology Dresden. Doctor of Sciences: 237, 2009.

[11] KOLDAEV, A. Basic principais for UAS development for non-military applications. International Conference \& Exhibition on Unmanned Aircraft Systems. Paris, 2009.

[12] VERNETTI, F.J. Origem da espécie, introdução e disseminação no Brasil. In: FUNDAÇÃO CARGILL. Soja: planta, clima, pragas, moléstias e invasoras. Campinas, 1983.

TECNO-LÓGICA, Santa Cruz do Sul, v. 25, n. 1, p. 122-134, jul./dez. 2021 Amatéria publicada nesse periódico é licenciada sob forma de uma http://creativecommons.org/licenses/by/4.0/ 